\title{
Breakfast habits, wellbeing and health of parkrunners
}

\author{
S. Reeves ${ }^{1}$, E. Grandy ${ }^{2}$, T. Mayan ${ }^{1}$ and J. Huber ${ }^{3}$ \\ ${ }^{1}$ University of Roehampton, London, SW15 4JD, \\ ${ }^{2}$ Cleveland Clinic, Cleveland, OH 44195, USA and \\ ${ }^{3}$ University of Brighton, Falmer, Brighton, BNI 9PH
}

Parkrun is a free weekly 5 kilometre run that to date more than $1,250,000$ people have participated in ${ }^{(1)}$. It has been previously reported that parkrun is a cost-effective community based intervention for improving public health ${ }^{(2)}$. Previous research has investigated the breakfast habits and health in a nationally representative UK sample ${ }^{(3)}$, however less is known about the breakfast habits and health of recreational athletes. The aim of this study was to report the breakfasting habits, and measures of health of parkrunners in the UK.

Recreational runners based in the UK were recruited through parkrun, and were asked to complete a cross-sectional web-based survey, based on questionnaires used in a previously published study of breakfast habits ${ }^{(3)}$. A total of 1,053 parkrunners completed the survey. Ethical approval was granted from the University of Roehampton and permission was given by the parkrun research board.

Of the 1,053 parkrunners recruited, $52 \%$ were male. The mean age of the total sample was $44 \cdot 2$ (SD 11.5) years. The mean self-reported BMI for males was 24.3 (SD 3.2) and for females 23.2 (SD 3.4) kg/m². $86 \%$ of parkrunners consumed breakfast every day, compared to $64 \%$ in a nationally representative UK sample ${ }^{(3)}$. Only $1.3 \%$ of parkrunners never consumed breakfast; the most common reason for skipping breakfast was not enough time $(n=119,54 \cdot 6 \%)$. Amongst breakfast eaters the most frequently consumed foods were porridge and muesli $(53.2 \%)$, cereals $(55.9 \%)$ and fruit (43.9\%), however the consumption of eggs and pastries more than doubled on weekends. On average both male and female participants partook in moderate to vigorous activity 5 days a week, $28 \% 7$ days a week. Mean time spent watching television per day was 107 (SD 72) min. compared with 177 (SD 118) min. in a nationally representative sample ${ }^{(3)}$. In terms of chronobiology $30 \%$ of participants could be described as morning types and only $1 \%$ as evening types; morning types did significantly more minutes per week of moderate to vigorous activity than intermediate types $(\mathrm{p}<0.001) .86 \%$ of the parkrunners reported good psychological wellbeing and $98 \%$ described their general health as good or above, compared to $63 \%$ and $74 \%$ respectively found in the nationally representative sample ${ }^{3}$. There were weak but significant correlations between breakfast frequency and general health (Rho 0.114), morningness (Rho 0.142) and wellbeing (Rho 0.130) (all $\mathrm{P}<0.01$ ) in the parkrunners.

The majority of parkrun respondents consumed breakfast regularly and more frequently than the general population and had lower levels of obesity as assessed by self-reported BMI. In addition parkrunners were more active, less sedentary and had higher levels of wellbeing and general health. Key limitations of the study are the self-selected participation and cross-sectional design. In general the data shows evidence for an overall healthier lifestyle amongst parkrunners.

1. Parkrun (2017) www.parkrun.co.uk. Accessed 3/4/17

2. Stevinson C, Hickson M (2013) Journal of Public Health 36, 268-274.

3. Reeves S, Halsey L, McMeel Y, Huber J (2013) Appetite 60, 51-57. 